\title{
"E1 funcionario viene a ser como una personificación del Estado". Conflictos y límites de la autoridad en el centro occidente colombiano, 1850-1925*
}

\begin{abstract}
EDWIN ANDRÉs Monsalvo
Profesor de la Universidad de Caldas (Colombia). Correo electrónico: edwinmonsalvo@omail.com. El autor es magíster en Historia de la Universidad Industrial de Santander (Colombia). Integrante del Grupo de Investigaciones Históricas en Educación e Identidad Nacional (Categoría A, Colciencias). Entre sus publicaciones recientes tenemos: en coautoría "Contra la moral i las buenas costumbres. El control de la vagancia y la prostitución en la frontera Sur de Antioquia, Manizales, Colombia 1850-1870” en Caravelle Vol. 104 (2015) y en coautoría "Milicias y milicianos en el interior de la provincia de Santa Marta (Virreinato de la Nueva Granada), 1770-1808" en Revista de Sociología y Antropología: Virajes Vol. 18, No. 1 (2016). Entre sus temas de interés están historia política.
\end{abstract}

Willian Alfredo Chapman Quevedo Profesor de la Universidad del Tolima (Colombia). Correo electrónico: wachapmanq@ut.edu.co. El autor es doctor en Historia Social y Política Contemporánea: Movimientos Sociales y Construcción de la Ciudadanía en el Mundo Contemporáneo en Perspectiva Comparada de la Universidad Internacional de Andalucía (España). Integrante del Grupo de Investigaciones Históricas en Educación e Identidad Nacional (Categoría A, Colciencias). Entre sus publicaciones recientes tenemos: en coautoría "La tuberculosis pulmonar en Barranquilla, 1930-1960" en Memorias. Revista Digital de Historia y Arqueología desde el Caribe Colombiano (2015) y "El concepto de sociabilidad como referente del análisis histórico" en Revista Investigación y Desarrollo Vol. 23, No. 1 (2015). Entre sus temas de interés están historia de Colombia siglos XIX y XX.

Miguel Antonio Suárez Araméndiz Profesor de la Universidad de Caldas (Colombia). Correo electrónico: miguel.suarez@ucaldas.edu.co. El autor es magíster en Historia de la Universidad Industrial de Santander (Colombia). Integrante del Grupo de Investigaciones Históricas en Educación e Identidad Nacional (Categoría A, Colciencias). Entre sus publicaciones recientes tenemos: en coautoría "Milicias y milicianos en el interior de la provincia de Santa Marta (Virreinato de la Nueva Granada), 1770-1808” en Revista de Sociología y Antropología: Virajes Vol. 18, No. 1 (2016) y "Conflictividad, delincuencia y justicia en el Departamento de Caldas, 1900-1925" en Revista Historia y Espacio Vol. 11 No. 45 (2015). Entre sus temas de interés están historia de las redes sociales, burocracia y construcción del Estado e historia regional.

Recibido: 26 de noviembre de 2015

Modificado: 13 de julio de 2016
Aprobado: 18 de mayo de 2016

Artículo de investigación científica

DOI: http://dx.doi.org/10.15648/hc.30.2016.10

Este artículo forma parte del proyecto: "Salubridad, Higiene y Criminalidad en los Departamentos del Atlántico y Caldas Durante la Primera Mitad del Siglo XX" financiado por la Universidad del Atlántico. Esta publicación está bajo una licencia Creative Commons Reconocimiento-NoComercial 4.0 
"El funcionario viene a ser como una personificación del Estado". Conflictos y límites de la autoridad en el centro occidente colombiano, 1850-1925

\title{
Resumen
}

Este artículo se propone estudiar las dificultades en el establecimiento de la autoridad en Manizales y el departamento de Caldas. A través del análisis de los juicios sumariales de primera y segunda instancia, en los casos de abuso de autoridad y resistencia a la misma, se muestran las dificultades enfrentadas por los funcionarios encargados de mantener el orden de policía. Asimismo, se evidencian las extralimitaciones de estos funcionarios, como rasgos característicos que pudieron deslegitimar las actuaciones oficiales. Se sostiene que los conflictos estudiados fueron parte del despliegue estatal en el centro occidente colombiano. Allí la reciente fundación de la mayoría de poblados, las distancias geográficas, la escasez de recursos y la cercanía de la burocracia local con los sujetos a vigilancia, hicieron de este un complejo pero dinámico proceso.

Palabras claves: estado, autoridad, irrespeto, abuso de poder.

"The official becomes as a personification of the State". Conflicts and limits of authority in the Colombian Western Centre, 1850-1925

\begin{abstract}
Abstrat
This article aims at studying the difficulties in the authority establishment in Manizales and departamento de Caldas. Through the analysis of trial investigation in first and second instance, in cases of authority abuse and resistance to it, difficulties faced by officers in charge of maintaining the police order are shown. In addition, the abuse of these officers is evident, as characteristic that could delegitimize the official actions. It is argued that the studied conflicts were part of the state deployment in the Colombian center west. There the recent foundation of most towns, the geographical distances, the resources scarcity and the near local bureaucracy with those subject to surveillance, made of this a complex but dynamic process.
\end{abstract}

Key words: state, authority, disrespect, power abuse.

“O servidor público vem a ser como uma personificação do Estado". Conflitos e limites da autoridade no centro ocidente colombiano, 1850-1925

\section{Resumo}

Este artigo propõe-se estudar as dificuldades no estabelecimento da autoridade em Ma- 
nizales e o departamento de Caldas. Através da análise dos julgamentos sumariales de primeira e segunda instância, nos casos de abuso de autoridade e resistência à mesma, mostram-se as dificuldades enfrentadas pelos servidores públicos encarregados de manter a ordem de polícia. Mesmo assim, se evidencian os excesso de poder destes servidores públicos, como rasgos característicos que puderam deslegitimar as atuações oficiais. Sustenta-se que os conflitos estudados foram parte do despliegue estatal no centro ocidente colombiano. Ali a recente fundação da maioria de povoados, as distâncias geográficas, a escassez de recursos e a cercania da burocracia local com os sujeitos a vigilância, fizeram deste um complexo mas dinâmico processo.

Palavras-chave: estado, autoridade, irrespeto, abuso de poder.

\section{"Le fonctionnaire tend à devenir une personnification de l'État". Conflits et li- mites de l'autorité dans le centre-ouest de la Colombie, 1850-1925.}

\section{Résumé}

Cet article a pour but d'étudier les difficultés liées à l'enracinement de l'autorité à Manizales et dans le département de Caldas. L'analyse des jugements immédiats de première et de seconde instance -dans les cas précis d'abus et de résistance à l'autorité- démontrent les difficultés rencontrées par les fonctionnaires chargés de faire respecter l'ordre. De même, les excès de pouvoir de ces fonctionnaires sont mis en évidence comme traits caractéristiques pouvant délégitimer les interventions officielles. Il est soutenu que les conflits étudiés ont fait partie du déploiement de l'État dans le centre-ouest de la Colombie où la fondation récente de la plupart de villages, les distances géographiques, la pénurie de ressources et la proximité de la bureaucratie locale avec les sujets à surveiller ont fait de ce processus, une question complexe mais dynamique.

Mots clés: l'état, autorité, irrespect, abus de pouvoir.

\section{INTRODUCCIÓN ${ }^{*}$}

En Colombia en los últimos tiempos, los medios de comunicación han

* Agradecimientos a los estudiantes del programa de Historia de la Universidad de Caldas Emanuel Márquez, Gloria Patiño, Carlos Aguirre, Luisa Arboleda, Andrés Delgado, Estiven Hincapié, Yessica Hoyos, Juan Jaramillo, Jhon Rodríguez y Cristian Tovar por su colaboración en la búsqueda de varios de los sumarios con los que se realizó este trabajo. 
desplegado una campaña que se interroga por la autoridad. Esta se basa en mostrar hechos en los cuales los agentes del orden en cumplimiento de su deber son burlados, golpeados e insultados constantemente por figuras públicas o transeúntes comunes. ¿Dónde está la autoridad?¹, tituló una de las revistas más importantes del país, y no se refería a la ausencia o presencia de uniformados, sino al irrespeto por parte de los subordinados hacia los agentes del orden. En esta discusión mediática se ha recurrido a entrevistar a científicos sociales, juristas y políticos de todo tipo para intentar explicar por qué está ocurriendo este fenómeno, pero se desconoce que este no es nuevo ${ }^{2}$.

Este artículo no pretende responder a la pregunta planteada por los medios de comunicación, sino hacer una arqueología histórica de la construcción de la autoridad local en el centro occidente colombiano, en especial de la que emana de la justicia local y los cuerpos de policía. Ello conlleva a un análisis del funcionamiento del Estado que no se pregunta tanto por dónde está la autoridad sino por cómo se constituyó, de qué manera se asumió, cuáles fueron las dificultades de los encargados de imponer el orden y cuáles las reacciones de los que debían obedecer.

Hace unos años Charles Tilly mostró cómo en los últimos siglos, las autoridades políticas en su búsqueda de amplios acuerdos integraron a distintos sectores marginales a los Estados nacionales hasta llegar a los regímenes democráticos actuales ${ }^{3}$. De esta manera dicho consenso convirtió al Estado en reflejo de la estructura social de su población. Este proceso conllevó a la necesidad de que las clases hegemónicas integraran a sus pro-

1 Revista Semana, 25 de marzo de 2015.

2 Existe una distancia entre la mera ocurrencia de un hecho social y la manera en que el cuerpo social lo reconoce y lo pondera. Como lo mostraron algunos estudios de las ciencias sociales de: Albert Cohen, Delinquent Boys. The Culture of the Gang (New York: The Free Press, 1955) y Stuart Hall, "El trabajo de la representación", en Representation: Cultural Representations and Signifying Practices. Stuart Hall (ed.), (Londres: Sage Publications, 1997) es la percepción que se construye sobre un determinado proceso social lo que lo transforma en un problema acuciante, en algo que preocupa a la sociedad y que consecuentemente esta intenta 'resolver'.

3 Charles Tilly, Coerción, capital y estados europeos (Buenos Aires: Alianza, 1993), 158. 
yectos la impronta de los sectores dominados en una negociación que fue dando forma al Estado moderno. De las razones de estos cambios se sabe poco, pero más de sus consecuencias: El incremento de los instrumentos de consenso respecto de los de coacción como medios de control político internos ${ }^{4}$.

Ya Weber había sostenido que las relaciones de dominación son la fuerza estructurante de una sociedad; aquellas que le otorgan su organización y estructura. según Weber esta dominación se ejerce mediante tres tipos ideales de autoridad: La legal -que es la que más nos interesa para este análisis- que se expresa en un sistema de normas racionales ejecutadas por empleados judiciales y administrativos a los cuales se les respeta porque representan la ley y no por la persona que ocupa el cargo. Esta es la expresión de la burocracia moderna. La tradicional que actúa en relación a la costumbre, y la carismática que es ejecutada por individuos con fuerte arraigo en la población. En realidad, los tres niveles weberianos actúan simultáneamente. Lo que supone que en las actuaciones de la burocracia intervienen la fuerza de la costumbre y las convenciones culturales de lo que cada sociedad define como carisma ${ }^{5}$.

A pesar de la difusión de este esquema de dominación, resulta complejo intentar ajustar modelos exógenos a las realidades estudiadas. Especialmente cuando dichos modelos son tomados de contextos distintos y por tratarse de elementos analíticos que en principio son propios de la sociología, injertados no con pocas complicaciones en los terrenos de la historia, de la ciencia política y de la antropología. Y aunque estas mismas disciplinas han aceptado casi al unísono la definición de Estado a partir del monopolio del uso legítimo de la fuerza física dentro de un territorio dado, cada vez se cuestiona de manera más directa y evidente los límites de la legitimidad de dicho uso, al mismo tiempo que aumentan la fuerza y la importancia de los mecanismos, actores e instituciones supranacionales ${ }^{6}$.

4 Ver los trabajos reunidos en: Ricardo Forte y Guillermo Guajardo (Coord.), Consenso y Coacción. Estado e instrumentos de control político y social en México y América Latina (Siglos XIX y XX) (México: El Colegio de México, El Colegio Mexiquense, 2000).

5 Max Weber, Economía y Sociedad (México: FCE, 1986).

6 Ricardo Forte y Guillermo Guajardo (Coord.), Consenso y Coacción, XXI... 
Pese a todo, no se desecha dicho esquema y de manera selectiva se toman algunos de sus principales postulados, lo que en realidad contribuye más a abrir nuevas preguntas que a responder las existentes. Por ejemplo, esto lleva a preguntarnos si la cuestión clave es quién gobierna o cómo se efectúa ese gobierno. En este orden de ideas, James Scott sostuvo que en todas las sociedades tanto los dominados como los dominadores mantienen un discurso oculto. Mientras que los de los subordinados representan una crítica a la autoridad a espaldas del dominador, las expresiones de los grupos hegemónicos articulan prácticas y exigencias de su poder que no se pueden expresar abiertamente ${ }^{7}$.

De allí la necesidad de comprender las prácticas políticas de la autoridad y la obediencia como actuaciones que llevan a cabo unos actores interesados en reproducir unas apariencias hegemónicas ${ }^{8}$. Por ello, como señala Scott "el jefe electo de una república debe dar la apariencia de que respeta a la ciudadanía y sus opiniones; un juez debe parecer que venera la ley". El poder se constituye en esta medida sobre la base de las apariencias.

7 James Scott, Los dominados y el arte de la resistencia (México: Ediciones Era, 2000), 21.

8 El concepto de hegemonía es tomado de Florencia Mallon "En este intento de arqueología política me ha parecido particularmente útil el concepto de hegemonía. Sin embargo, no igualo hegemonía con una creencia en -o una incorporación de- la ideología dominante. En cambio, defino hegemonía de dos maneras distintas, aunque a veces relacionadas. Según la primera, la hegemonía es un conjunto de procesos incubados, constantes y en curso, a través de los cuales las relaciones de poder son debatidas, legitimadas y redefinidas en todos los niveles de la sociedad. Según esta definición, hegemonía es proceso hegemónico: puede existir y existe en todas partes, en todo momento. De acuerdo con la segunda, la hegemonía es un punto final real: el resultado de un proceso hegemónico. Se llega a un equilibrio siempre dinámico o precario, un contrato o acuerdo entre fuerzas disputantes. Quienes se hacen con el poder rigen, entonces, a través de una combinación de coerción y consentimiento. En palabras de Philip Corrigan y Derek Sayer, eso es una revolución cultural: la generación de un proyecto social y moral común que incluye nociones de cultura política del pueblo y de la élite. Si contemplamos la hegemonía como un proceso, todos los niveles de la política se convierten en terrenos intervinculados, en los que el poder es disputado, legitimado y redefinido. Unos proyectos políticos siempre derrotarán a otros, y unas facciones predominarán sobre otras. Las interacciones entre diferentes terrenos políticos - por ejemplo, entre las comunidades y las regiones, o entre las regiones y el estado central- no solo redefinen a cada uno internamente, sino que también colaboran a redefinir el equilibrio de fuerzas entre ellos. Florencia Mallon, "Reflexiones sobre las ruinas: formas cotidianas de formación del Estado en el México decimonónico”, en Aspectos cotidianos de la formación del Estado. La revolución y la negociación del mando en el México moderno Comp. Golbert M. Joseph y Daniel Nugent (México: Ediciones Era, 2002), 105-106.

9 James Scott, Los dominados..., 35. 
En el caso que nos interesa el policía y el juez serán respetados en la medida que aparentaban ser respetuosos de la ley; cuando esta imagen se rompía sucedía lo mismo con la autoridad que emanaba de su posición. La obediencia a la ley debía ir aparejada con un sistema de disciplina y castigo desplegado por la burocracia local para ganarse el respeto y la legitimidad. Idealmente, este sistema conduciría a que la mayoría de los subordinados consintieran y obedecieran no por haber aprehendido las normas sino porque habiendo una estructura de vigilancia, recompensas y castigos, consideraban más prudente asentir. Sin embargo, ello supone la existencia de un aparato coactivo lo suficientemente fuerte para provocar miedo, convicción o respeto ${ }^{10}$. $\mathrm{Y}$ aunque las fuentes muestran esfuerzos razonables para intervenir en las vidas de los sujetos a vigilancia como el alcalde que camina las calles del mercado pidiendo las guías de los cerdos en venta ${ }^{11}$, o el que aparece a medianoche persiguiendo el ruido de una música para imponer multas por bailes prohibidos $^{12}$; la evidencia también sugiere cierto grado de permisividad frente al delito con castigos ejemplarizantes esporádicos.

Eric Hobsbawn sintetizó las razones en tres esquemas que explican las dificultades de las autoridades para imponerse frente a sus subordinados. Según el historiador británico, el poder se ha visto limitado porque los medios de control de que disponían los funcionarios eran inadecuados, porque su adecuación dependía hasta cierto punto de la disposición de los súbditos a obedecer y de su capacidad de evitar obedecer y porque (en parte por esta razón) las autoridades trataron de controlar directamente solo algunas parcelas de las vidas de sus súbditos ${ }^{13}$.

En este modelo se hacen evidentes dos formas de dominación: El consenso que evidencia un acuerdo -basado en los valores y normas compartidos- entre los miembros de una comunidad y la coacción que "remite

10 James Scott, Los dominados..., 228

11 "Colecturía de Hacienda" (Manizales 2 de diciembre de 1871), Archivo Municipal de Manizales (AMM), Fondo Histórico, Libro 40, Caja 12, ff. 263-271.

12 "Sumario por un baile sin permiso contra Pedro P. González" (Manizales, 19 de marzo de 1860), AMM, Fondo Histórico, Caja 5, Libro 16. f. 190.

13 Eric Hobsbawn, Bandidos (Barcelona: Crítica, 2011), 24. 
a una relación de fuerza asimétrica, donde un poder dominante obliga a los subordinados a conformarse o ajustarse a los modelos legítimos de convivencia social"14. Tanto el consenso como la coacción se ejecutan de manera conjunta por lo que es necesario estudiarlos simultáneamente. De allí que sea válido preguntarse con Scott “¿cuántas golpizas, encarcelamientos, ejecuciones, tratos secretos, sobornos, amenazas, concesiones y, muy importante, cuántas manifestaciones públicas de grandeza, de castigos ejemplares, de beneficencia, de honestidad espiritual, etcétera..."15, se necesitan para mantener en funcionamiento la autoridad?

Siguiendo las ideas de Hobsbawn y Scott, la autoridad no aparece de un día a otro, se necesita de un proceso en el que la fuerza de la coacción se haga eficaz al mismo tiempo que el consenso para aceptar la autoridad -aunque sea de manera conveniente- se haga público. En este proceso juega un papel fundamental lo que Balandier llamó "el teatro del poder". Según sus palabras las técnicas dramáticas no se utilizan solo en el teatro sino también en la dirección de la ciudad. El gobernante debe comportarse como un actor político si quiere conquistar y conservar el poder. Su imagen, las apariencias que provoca, pueden entonces corresponder a lo que sus gobernados desean hallar en él, "asumamos el riesgo de una fórmula: el consentimiento resulta, en gran medida, de las ilusiones producidas por la óptica social"16.

En este orden de ideas, este artículo se propone analizar -lo más a ras de tierra posible- las formas de obediencia y resistencia al poder en las relaciones entre jueces, alcaldes, policías y los judiciables del centro occidente colombiano, mediante el estudio de los juicios sumariales de primera y segunda instancia en los delitos de irrespeto y abuso de autoridad entre 1850 y 1925 . El trabajo analiza un total de 51 juicios sumariales por resistencia o abuso de la autoridad durante este período ${ }^{17}$ que evidencia una

14 Ricardo Forte y Guillermo Guajardo (Coord.), Consenso y Coacción, xv...

15 James Scott, Los dominados..., 71.

16 George Balandier, El poder en escenas. De la representación del poder al poder de la representación. (Barcelona: Paidós, 1994), 16.

17 Ello puede deberse también a que solo revisamos los archivos de primera instancia en Manizales, Aranzazu y Salamina. Para los demás casos solo tuvimos en cuenta los juicios de segunda instancia. 
tasa relativamente baja en el juzgamiento de esta infracción, especialmente si se la compara con los delitos de hurto, robos, fraude a la renta, juegos prohibidos o vagancia ${ }^{18}$. Sin embargo, resulta relevante para los intereses de esta investigación que muchos casos hayan pasado a la segunda instancia judicial lo que denota no solo el recurso a la justicia por parte de la población rural sino la importancia que tanto magistrados de la judicatura como jueces locales y alcaldes otorgaron a este tipo de procesos utilizando argumentos "alarmantes" para referirse a las supuestas posibles consecuencias que dichas prácticas podrían tener en el futuro. El trabajo sigue el método histórico hermenéutico, hace la respectiva crítica interna y externa y coteja la información recolectada mediante fichas de investigación con otras fuentes primarias y secundarias. Optamos por presentar los resultados en términos diacrónicos aceptando que la legislación varió a lo largo del período ${ }^{19}$. Sin embargo consideramos que en su aspecto central -el castigo por desobedecer y abusar de la autoridad-se mantuvo incólume ${ }^{20}$.

Cabe aclarar también que algunos juicios empezaron por delitos de heridas, riñas, injuria o asesinato y posteriormente derivaron hacia las relaciones con las autoridades porque uno o varios implicados eran funcionarios públicos.

18 Edwin Monsalvo Mendoza y Ana María Bedoya Sánchez, "El complejo establecimiento del orden de policía en una sociedad de frontera. Manizales 1853-1871”, Virajes. Revista de Sociología y Antropología Vol. 16 No. 2 (2014): 41-65.

19 El Código Penal de 1837 dedicó el título quinto, capítulo I y II a especificar los "delitos y culpas contra los funcionarios o empleados públicos en el ejercicio de sus funciones y de los que se las usurpan o proceden con amenazas". Allí se tipifica como delito los casos de desobediencia a las autoridades (Art. 297) y los daños, ultrajes e injurias contra funcionarios públicos (Art. 294). Las penas iban desde tres días de arresto a cuatro meses por lanzar expresiones, palabras, gestos o actos de desprecio y por desobediencia a la autoridad; las penas eran de cuatro a treinta días de arresto o cuatro a 30 pesos. Sin embargo si se trataba de altos funcionarios como Presidente o Vicepresidente podían llegar hasta un año de prisión. Código Penal (Junio 27). El Senado y la Cámara de Representantes de la Nueva Granada, reunidos en Congreso, han venido en decretar y decretan el siguiente Código Penal. Dado en Bogotá a 29 de mayo de 1837. El Código Penal de 1890 aumentó las penas y fue más específico al definir en su capítulo quinto los delitos de resistencia a ejecuciones de leyes, actos de justicia y providencias de las autoridades públicas dando seis meses a dos años de prisión, cuestión que podía empeorar duplicando la pena si se usaban armas o actuaban más de cuatro personas. El artículo 242 advertía que levantar la voz a una autoridad era tipificado como resistencia y el artículo 246 daba una pena de apercibimiento judicial, arresto de dos a doce días o multa de dos a doce pesos a los que no prestaran auxilio a las autoridades cuando estas se los solicitaren. Ley 19 de 1890. Código Penal (18 de octubre). Bogotá, Imprenta de la Nación.

20 Como lo señaló Bloch los seres humanos no cambian de vocabulario cada vez que mudan de costumbres, de modo que "la inevitable variabilidad histórica de los contenidos de las categorías no solo invalida esa pretensión sino que constituye también la fuente de todas las trampas nominalistas en que puede descarrillar el conocimiento histórico". Marc Bloch, Introducción a la Historia (México: FCE, 1979) [primera edición de 1949]. 
También debemos aclarar que cuando nos referimos al centro occidente colombiano estamos haciendo referencia a una región culturalmente construida que integra territorios de los actuales departamentos de Caldas, Risaralda y Quindío ${ }^{21}$. Sin embargo ante los constantes cambios de jurisdicciones optamos por homogeneizar el territorio bajo un concepto extemporáneo que permite englobar los distintos municipios estudiados. El trabajo lo hemos dividido en tres partes, en la primera se muestran las dificultades por constituir una burocracia moderna; en la segunda se describen los irrespetos a las autoridades y en la última sus abusos. Al final intentamos dar cuenta de la complejidad en el proceso de construcción de los mecanismos de obediencia a la autoridad.

\section{UNA BUROCRACIA NO TAN MODERNA}

El marco temporal tomado para este trabajo obedece a la necesidad de dar una mirada a la autoridad dentro de un período de mediana duración que empieza con la fundación de Manizales hasta 1925, caracterizado por el proceso de poblamiento, auge de la economía cafetera, bonanza económica y crecimiento demográfico. Es también el espacio de tiempo en el que se desarrollaron los llamados procesos de modernización. Las transformaciones que sucedieron en estos años produjeron cambios: aparecieron nuevos actores que modificaron el mundo social (obreros, asalariados, sindicatos, agremiaciones) y el cultural, las comunicaciones, los transportes, la industria, el comercio y las finanzas tuvieron un marcado auge. Sin embargo, algunas cosas permanecieron como la exigencia de mantener el orden social frente a unas instituciones que tardaron en acomodarse al nuevo ritmo de los cambios sociales ${ }^{22}$.

Evidentemente en la segunda mitad del siglo XIX, la mayoría de municipios abordados en este trabajo tenían una fundación reciente; su pobla-

21 Durante algún tiempo se le denominó el Gran Caldas a esta jurisdicción; sin embargo preferimos no cometer el anacronismo de usar una categoría político-administrativa que solo tiene aplicación para 20 de los 75 años que aborda el estudio. Por ello preferimos el uso de una categoría geográficocultural que si bien no fue usada durante la época, abarca este espacio.

22 Edwin Monsalvo, Miguel Suárez y David Herrera. "Conflictividad, delincuencia y justicia en el Departamento de Caldas, 1900-1925”, Historia y Espacio, 45 (2015): 97-118. 
ción era escasa y los avances económicos y administrativos iban desarrollándose lentamente. Años después de haber sido creadas las parroquias de Manizales, Neira y Salamina las autoridades allí instaladas habían asumido las funciones judiciales, administrativas y de policía que permitieron el sostenimiento fiscal, social y político de estos territorios. Dichos funcionarios eran los representantes del Estado y a pesar de que varias circunstancias se confabularon para complejizar su trabajo tales como la distancia geográfica con la capital provincial, estatal o departamental, la escasez de burócratas, los bajos o inexistentes salarios, estos empleados actuaron interviniendo en aspectos de la vida de los habitantes que desde sus perspectivas era necesario corregir. Por supuesto no se trató de un régimen de vigilancia y castigo como el sugerido en los estudios de Foucault, pero sí permitían construir una pedagogía social de la autoridad y el orden.

De estas dificultades, tenemos conocimiento por la correspondencia oficial de la alcaldía y el Cabildo Municipal de Manizales que constantemente recibieron quejas de los alcaldes, jueces y comisarios para que se mejoraran las condiciones de sus despachos ${ }^{23}$, se les aumentara el salario o que finalmente se les pagara ${ }^{24}$. Al punto que algunos jueces debían remunerar con su propio peculio el salario del secretario como le ocurrió al juez parroquial de Manizales Eusebio Londoño en $1865^{25}$.

Durante el siglo XIX los alcaldes y jueces eran miembros del patriciado local pero no por ello se caracterizaban por tener vastos conocimientos legales y administrativos. En ocasiones escasamente sabían leer y escribir. Antonio María Arango, miembro notable de la parroquia de Manizales en 1854 solicitó a los vocales del Cabildo que permitieran la creación del cargo de secretario del despacho del jefe municipal, puesto que sería de gran

23 “Correspondencia Oficial 1860. Juez $1^{\circ}$ parroquial José Ramírez al Presidente del Cabildo" (Manizales, 3 de febrero de 1860), AMM, Fondo Histórico, Caja 4, Libro 12, Legajo 33, f. 170. "Correspondencia Oficial 1855. Antonio Ceballos alcalde parroquial a vicepresidente del cabildo" (Manizales, 2 de julio de 1855), AMM, Fondo Histórico, Caja 4, Libro 12, Legajo 2, f. 59.

24 "Correspondencia Oficial 1855. Bernardino Jaramillo juez parroquial a Presidente Cabildo" (Manizales, 5 febrero de 1855), AMM, Fondo Histórico, Caja 4, Libro 12, Legajo 2, ff. 37 y 42.

25 "Correspondencia Oficial 1855. Eusebio Londoño juez parroquial al señor presidente del cabildo" (Manizales, 22 marzo de 1865), AMM, Fondo Histórico, Caja 4, Libro 12, Legajo 11, f. 371. 
ayuda a los empleados del distrito, "donde casi todos caresemos de los conocimientos necesarios para desempeñar; porque rara vez sucede que sepa leer i escribir el individuo encargado de la alcaldía"26.

Los secretarios fueron funcionarios claves en el entramado jurídico y social de la parroquia. A diferencia de los alcaldes y jueces no eran miembros del patriciado local, pero tampoco de los sectores populares como los comisarios. Eran versados en leyes, redactaban la correspondencia, transcribían las declaraciones orales de los testigos y acusados en los sumarios de policía y leían todos los documentos que llegaban al despacho municipal. Así mismo, permanecían durante todo el día en las instalaciones, atendían al público y en ocasiones entregaban correspondencia. Además, al ser un cargo permanente, el alcalde que llegaba encontraba a un funcionario conocedor de los negocios de su despacho agilizando la administración pública; en fin, los secretarios desarrollaron buena parte de las funciones del alcalde y del jefe de policía.

Y si los alcaldes y jefes de policía, notables locales, sufrían dificultades para la administración de justicia, la situación de los comisarios de policía, era aún más desfavorable. Estos eran miembros de la plebe, analfabetos y vinculados laboral y emocionalmente con los mismos individuos que debían vigilar, enviar a la cárcel, imponerles multas y denunciar. A pesar de ello, los comisarios y policías tuvieron que afrontar su tarea en medio de muchas dificultades como su carente formación burocrática, poca motivación derivada de los exiguos y en ocasiones inexistentes salarios y porque tenían relación estrecha con los sujetos que debían vigilar.

En su mayoría los encargados de mantener el orden de policía no usaban armas, algunos solo portaban la "vara de la justicia"27, mientras que los delincuentes a perseguir sí las tenían. En este contexto, no resultaba sencillo

26 "Correspondencia Oficial 1855. Antonio María Arango, alcalde del Distrito a vocales del Cabildo" (Manizales, 5 de mayo de 1854), AMM, Fondo Histórico, Caja 4, Libro 12, Legajo 2, f. 10. provincias, cantones i distritos parroquiales”, en Recopilación de Leyes de la Nueva Granada, ed. Lino de Pombo (Bogotá: Imprenta de Zoilo Salazar, 1845), 41-61. Esta luego se transformó en un palo que servía además de defensa. 
para los agentes de policía ejercer su autoridad, toda vez que debían intervenir en riñas como le ocurrió al celador de la renta de licores Marco Antonio Zuluaga en La Esperanza, corregimiento de San Bartolomé (Pácora) en 1923 quien resultó asesinado con arma de fuego por Francisco Henao, un contrabandista y propietario de una destiladora. Aunque en este caso se trataba de un delincuente; el ejemplo muestra la vulnerabilidad de los agentes del Estado desprovistos de los elementos necesarios para ejercer su función quedando a merced de un contrabandista armado. De igual forma fue herido el alcalde de Pereira en 1897 mientras intentaba separar a dos hermanos que reñían ${ }^{28}$.

Solo a finales de siglo XIX se uniformaron con vestidos a los agentes de policía, con lo que se esperaba que "de esta manera el distintivo de la autoridad se haga más respetuosa y evitar la frecuente confusión con los demás paisanos cuando ella debe actuar" ${ }^{29}$; sin embargo el número de oficiales siempre pareció ser insuficiente y la organización policial compleja. A principios de siglo XX existían los agentes de policía municipal, llamados "municipales" que eran dependientes del Alcalde y eran nombrados por este; además estaban los departamentales que no dependían del Alcalde, usaban uniformes parecidos distinguiéndose solo por el gorro colorado de los primeros ${ }^{30}$.

Como si estas no fueran suficientes penurias, durante los períodos de guerra los escasos recursos desaparecían por completo. La administración de justicia quedaba casi suspendida. Los salarios de los empleados también se veían mermados ${ }^{31}$. Aunque a partir de la reforma judicial de 1897 la situación mejoró un poco -sobre todo en la capital Manizales- el siglo XX empezó con una larga guerra que volvió a complicar la situación.

28 "Por evitar una riña", El iniciador. Literatura, noticias, industria y comercio, 8, febrero 28 de 1897 , 31.

29 "Policía", El iniciador. Literatura, noticias, industria y comercio, 9, marzo 7 de 1897, 39.

30 "Carta de Rufino Gómez a Enrique Otero. Cartago, diciembre de 1917”, Archivo Historial, I: 6, enero de 1919, 264. En ambos casos se trataba de cuotas burocráticas.

31 "Correspondencia Oficial 1855. Alejandro Londoño prefecto departamental al señor presidente de la Corporación municipal de Manizales” (Sonsón, 15 junio de 1864), AMM, Fondo Histórico, Caja 4, Libro 12, Legajo 60, f. 250. 
Las complejidades administrativas que tuvieron que asumir los funcionarios estatales en estos territorios, quizá explica las demoras en los procesos judiciales estudiados. De allí que los retardos fueran menos evidentes en Manizales, capital del departamento y asentamiento de lo más cercano a una burocracia moderna en el territorio caldense. Sin embargo, el panorama en los municipios era desolador como lo señalaron los magistrados de la judicatura cuando notaron que había 23 procesos que expiraron y que los jueces habían tardado más de una década en fallar. Esta situación fue calificada por los juristas como un "triste monumento de pereza, desidia, incapacidad" 32 . En estos sumarios encontraron causas de heridas y hurtos que databan desde 1903 y que no estaban resueltas o que habían prescrito por la aparente desidia de los jueces de Anserma, Santuario y Riosucio. Aunque las excusas de los doctores Manuel Tiberio, Manuel Ospina y Andrés Zapata por el incumplimiento de sus funciones fue el excesivo número de procesos que debían llevar; esto no bastó para que fueran judicializados por responsabilidad en los trámites ordinarios, en especial contra Zapata, por las omisiones o demoras ocasionadas mientras fue juez municipal en el circuito de Anserma entre 1911 y 1913, y que fue nombrado en el mismo cargo en Angelopolis en el departamento de Antioquia.

Se desconoce si la demora se produjo por la desidia del juez Zapata, pero si se observan las causas que condujo otro togado en el circuito judicial de Salamina, es posible tener una idea del volumen de procesos que debían llevar. Entre 1911 y 1913, el juzgado de Salamina falló 50 causas criminales, y a ello habría que sumar las causas ordinarias, los juicios civiles y otras actividades que desempeñaban los jueces ${ }^{33}$.

Pese al hecho de que estos funcionarios eran abogados, la abrumadora cantidad de procesos frenaban la marcha de la justicia. Y ni qué decir de los jueces parroquiales del siglo XIX, alcaldes y policías que debían cumplir distintas funciones, entre ellas resolver en primera instancia los casos de violación a las normas de policía.

32 "Tribunal Superior del Distrito judicial. Dictada en la causa contra los jueces de Circuito por responsabilidad, Manizales, 14 de abril de 1916”, Revista Judicial de Caldas, 212 (abril 15 de 1917), 91.

33 Juzgado Promiscuo de Salamina, Miscelanea, 1913, ff. 4-34. 
En ocasiones las demoras no eran solo de la justicia sino de los implicados. Por ejemplo Casimiro Bartolo tardó dos años en denunciar a Espíritu Santo Bueno por unas heridas causadas en una riña en Marmato. Las heridas ocurrieron en 1902, la denuncia en 1904 y la sentencia fue proferida en 1908. Por supuesto que ante el tiempo transcurrido desde la ocurrencia de los hechos la evaluación de los peritos solo contó con la valoración de una cicatriz que quedó de la riña, así mismo las declaraciones de los testigos lucían desdibujadas porque estos olvidaban las fechas de los sucesos y perdían precisión en los detalles.

Por distintas razones, la ralentización del funcionamiento del sistema judicial era evidente, más aún en los territorios periféricos. Ello ayuda a entender por qué Miguel Cosma, un egipcio residente en Pensilvania, desesperado por los pocos avances de una denuncia de robo que había presentado ante el Juzgado Municipal dos años antes, injurió a Francisco Duque secretario del despacho porque este aparentemente era inepto para "ejercer el empleo", además porque con su actitud "patrocina ladrones" e hizo otros señalamientos contra el honor, el crédito y la dignidad del funcionario, dirigiendo "expresiones contumeliosas" 34 . Este desahogo frente a un funcionario no sirvió para acelerar los trámites, pero en cambio le costó pasar un mes en prisión por insultar a una autoridad.

Pero los procesos judiciales también se retrasaban por las demoras en la marcha de algunas alcaldías e inspectorías, como ocurrió con las quejas presentadas por la judicatura contra los funcionarios de Apía ${ }^{35}$. La distancia geográfica, los abruptos caminos, la escasez de presupuesto, las guerras, la pobre formación de los empleados y su cercanía con los subordinados llevan a pensar que esta era menos una burocracia en el sentido moderno del término y más un conjunto de funcionarios que si bien representaban

34 "Tribunal Superior del Distrito judicial. Dictada en la causa contra Miguel Cosma por los delitos de Sustracción de documentos custodiados en una oficina pública, y contra la persona de un empelado en actual ejercicio de sus funciones. Pensilvania a 23 de enero de 1913”, Revista Judicial de Caldas, 122, Manizales (febrero 15 de 1913), 914.

35 "Tribunal Superior del Distrito judicial. Dictada en la causa contra los jueces de Circuito por responsabilidad. Manizales a 14 de abril de 1916”, Revista Judicial de Caldas, 212, Manizales (abril 15 de 1917), 91. 
al Estado, estaban inmersos en una maraña de relaciones, conflictos y familiaridades que hicieron del ejercicio de la autoridad en estos territorios un proceso complejo ${ }^{36}$. No obstante, con todos sus bemoles y particularidades logró asentarse como se muestra a continuación

\section{“SE CREE El Dictador DE ESTE PUEblo!” y OTROS Discursos IRRESPE- TUOSOS DE LA AUTORIDAD}

El hecho de que durante el siglo XIX, los juicios de policía fueran llevados por vecinos de la parroquia, preocupó a algunos individuos que notaron las "injusticias" del sistema que aplicaba una justicia selectiva, dependiendo de las relaciones del sindicado con las autoridades locales. Sin embargo, en teoría la misma condición de vecino que los enredaba en la trama social interior de la parroquia, otorgaba a los alcaldes y policías la autoridad para ejercer justicia ${ }^{37}$.

En el siglo XX los jueces no fueron el objeto de este ataque ya que se trataba de abogados graduados, pero sí continuaron siéndolo otros funcionarios como los secretarios de los juzgados, alcaldes y especialmente los miembros de la policía. Es decir aquellos con los cuales los ciudadanos debían interactuar cotidianamente cuando necesitaban la intervención estatal o porque esta aparecía para regular sus comportamientos.

La cercanía entre autoridades policiales y judiciables fue uno de los asuntos que más causaba inconvenientes en el funcionamiento de ambos cuerpos, ya que aquello que en principio debía otorgar la autoridad para el mando, en ocasiones se constituía en la razón de la desobediencia. El exceso de confianza, el compadrazgo, la consanguinidad o el conocer los vicios y defectos de la autoridad se constituyeron en los elementos de juicio uti-

36 Ya Skocpol destacó la importancia de estudiar a los funcionarios del Estado para comprender la relación entre las condiciones internacionales, las presiones de las estructuras socioeconómicas y los intereses de los grupos políticos en la creación del contexto para las revoluciones sociales. Theda Skocpol, Los Estados y las revoluciones sociales (México: Fondo de Cultura Económica, 1983), 6566

37 Raúl Fradkin, “Justicia, policía y sociedad rural. Buenos Aires, 1780-1830”, en Las escalas de la historia comparada. Dinámicas sociales, poderes políticos y sistemas jurídicos, Tomo II, coords. Marta Bonaudo, Andrea Reguera, Blanca Zeberio (Buenos Aires: Miño y Dávila SRL, 2008), 275. 
lizados para evadir la responsabilidad de obedecer una orden oficial. Los hechos ocurridos en 1916 que conllevaron al asesinato de Gabriel Castro por Manuel A. Díaz, quien además fue acusado de resistirse con armas al inspector del corregimiento Abel Marín, permiten explicar lo anterior ${ }^{38}$. Ante una pelea callejera en el corregimiento de Colón, distrito de Calarcá intervino rápidamente el inspector y capturó a Manuel Díaz, Marco Giraldo y Salomón García. Sin embargo, este mismo funcionario dejó libre a Díaz -que era su cuñado- porque supuestamente necesitaba curar una herida, con el compromiso de que no podría salir de su casa. A pesar de ello, Díaz salió a la calle lo que provocó la reacción de algunos vecinos y obligó al inspector a volver a capturarlo. El judiciable se resistió al arresto, se encerró en una casa y gritó varios improperios contra el inspector quien le manifestó a Marín en una voz que refleja su cercanía "Vea Toño, hágame el favor de atender a la autoridad"; la respuesta de Díaz fue sacar un arma y disparar un tiro al grupo de personas que estaban alrededor. Finalmente, fue capturado, juzgado y sentenciado a pagar 30 meses de presidio por el homicidio.

Además del detalle descriptivo de la narración de los testigos, esta permite asir la idea de la familiaridad entre el judiciable y la autoridad, no solo por el vínculo de parentesco que poseían, sino por la cercanía y amabilidad de la conversación y las libertades que le otorgaban estas relaciones para evadir la acción policial. Podría suponerse acaso que si este hubiera sido puesto preso como los demás intervinientes en la riña, se hubiera evitado un asesinato y la burla a la autoridad, pero la familiaridad procuró atenuar el castigo lo que trajo consecuencias más graves para el corregimiento.

Las actuaciones del jefe de policía fueron el resultado no de la aplicación estricta de la ley, sino de las relaciones que existían en las sociedades locales aplicando una justicia equitativa ${ }^{39}$ e intentando siempre conservar el orden social establecido y las lealtades de los procesados con las redes internas de

38 "Tribunal Superior del Distrito judicial. Dictada en la causa contra Manuel Díaz por los delitos de homicidio y resistencia a la autoridad. Calarcá a 20 de febrero de 1916", Revista Judicial de Caldas, 219, Manizales (agosto 1 de 1917) 149-152.

39 Paolo Grossi, "¿Justicia. Como ley o ley como justicia? Anotaciones de un historiador del derecho", en Mitología jurídica de la modernidad, Paolo Grossi (Madrid: Editorial Trotta, 2003), 21-38. 
$\operatorname{poder}^{40}$. En otro trabajo se mostró las negociaciones a que recurrió la autoridad con los infractores a los juegos prohibidos imponiendo sanciones bajas que cumplían el papel de representar la justicia y el Estado; pero que al mismo tiempo, los jugadores, que eran miembros de la sociedad local, cumplían el deber de pagarlas y contribuir así con el teatro del poder ${ }^{41}$.

Sin embargo, como se ha señalado, la autoridad es un proceso que debe asirse permanentemente en la comunidad, por lo tanto en su concreción intervienen distintos factores. Así las cosas, los juicios por irrespeto evidencian además de su realización, el control que tenían las autoridades sobre este tipo de casos. De esta manera, aun cuando estos pueden ser considerados como relativamente pocos, para los contemporáneos no era un problema de cantidad sino de los efectos que uno solo de estos casos podía provocar. La negativa abierta a cumplir con una puesta en escena de la autoridad, era considerada una forma particularmente peligrosa de insubordinación, aun cuando esta se produjera bajo los efectos del alcohol. James Scott llamó la atención acerca de la importancia de analizar los actos de insubordinación "porque cualquier negativa particular a obedecer no es solo una pequeña grieta en una pared simbólica: implica necesariamente un cuestionamiento de todos los otros actos que esa forma de insubordinación implica"42. A continuación se presentan algunos ejemplos de ello; Jesús Quintero fue sancionado a pagar una multa de 10 pesos por desobedecer al alcalde que le pidió que llevara al reo José María Caicedo a Cartago ${ }^{43}$. A José Antonio González 5 pesos por “manotiar” y gritar al jefe municipal Rafael Jaramillo porque este mandó a hacer un caño en medio

40 Hace varios años que Giovanni Levi planteó las diferencias que existen entre aquellos países en los que la ley restringe la capacidad de los jueces para interpretar la ley, y países en los que el origen teológico del principio de justicia deja a los jueces un margen muy amplio de interpretación a través de lecturas analógicas y equitativas. Levi sostuvo que en estos últimos, se desplegó una justicia equitativa, otorgando un mayor rol al juez, ya que este se considera un intérprete de la ley, mediante lo que él denominó como "reciprocidad mediterránea". Al decir de Levi, existiría "un sentido común de justicia" que muchas veces entra en contradicción con las reglas jurídicas codificadas. Giovanni Levi, "Reciprocidad mediterránea”, Hispania, LX/1: 204 (2000): 103-126.

41 Edwin Monsalvo Mendoza y Héctor Miguel López Castrillón, "La acción policial en un territorio periférico. La Justicia en la Parroquia de Manizales 1855-1865”. Memoria y Sociedad, Vol. 18 No. 37 (2014): 113-130.

42 James Scott. Los dominados..., 242.

43 "Sumarios iniciados y resueltos por la Alcaldía de Manizales entre 1855 y 1870, Causa Criminal sobre responsabilidad de la fuga de un reo”, AMM, Fondo Histórico, Caja 5 libro 16, Legajo 3, f. 140r. 
de la propiedad de su patrón y desafió su autoridad manifestándole que "quién le había dado esa facultad, que era un arbitrario", añadiendo que Jaramillo era "el dictador de este pueblo"44. Manuel Osorio, un comisario de policía analfabeto en 1865 solicitó el apoyo a sus vecinos Hilario Parra y Avelino Castañeda para custodiar los presos de la cárcel, pero estos se negaron con el argumento de que iban para una fiesta y le dijeron que eran un "imprudente i falto de educación; que esas no eran palabras para hablarle a los hombres", Castañeda agregó que "no venia a guardiar, que él no le obedecia al comisario" 45 . Finalmente, el jefe de policía Rafael Jaramillo los castigó con 5 pesos de multa que no pagaron y fueron obligados a realizar trabajos en obras públicas. Igual ocurrió con Andrés Valencia, Joaquín Zapata y Clemente Ceballos, quienes fueron acusados de desobediencia y burla contra la autoridad, toda vez que no auxiliaron al Comisario de Policía Jesús Cifuentes cuando este iba en persecución de Antonio Hernández, un borracho que lo había golpeado al momento en que el comisario intentó apresarlo por beodez escandalosa ${ }^{46}$.

Comparadas con las penas impuestas a los infractores por juegos y bailes prohibidos puede considerarse que estas eran más altas, pero eran menores a las producidas por los delitos de vagancia y fraude a la renta que se calculaban de acuerdo al valor de la mercancía. Así las cosas, parecía que las autoridades sancionaban con más fuerza las desobediencias que la infracción de una norma. De esta forma el castigo mediante multas mostraba la cara fuerte del Estado: la coercitiva evidenciando la importancia de mantener el consenso aun cuando fuera por la fuerza. De allí que desde Salamina el prefecto del departamento del Sur Norberto Gómez haya manifestado la necesidad del cumplimiento de las penas por irrespeto a la autoridad recordando al alcalde que bajo el ordenamiento jurídico existente "lo esencial de las penas convencionales es el que ellas sigan inmediatamente a la falta como la sombra sigue al cuerpo que la produce" 47 .

44 "Sumarios iniciados y resueltos por la Alcaldía de Manizales entre 1855 y 1870, causa por irrespeto a la autoridad", AMM, Fondo Histórico, Caja 5, Libro 16, Legajo 6, f. 298v.

45 "Sumarios iniciados y resueltos por la Alcaldía de Manizales entre 1855 y 1870, Policía sumario instructivo para averiguar las faltas que cometieron Hilario Parra, Abelino Castañeda", AMM, Fondo Histórico, Caja 5, Libro 16, Legajo 6, f. 412r.

46 "Sumarios iniciados y resueltos por la Alcaldía de Manizales entre 1855 y 1870, Sumario Delito Infracción", AMM, Fondo Histórico, Caja 5, Libro 16, Legajo 6, f. 442r.

47 "Norberto Gómez a Prefectura departamento del sur, Salamina 13 de marzo de 1874. Procedimiento contra Germán Uribe por desobediencia”, AMM, Fondo Histórico, Caja 17, Libro 57, f. 326. 
La contundente afirmación del poder a través de multas o prisión se constituían en castigos ejemplarizantes que cumplían el propósito de que otros perdieran el ánimo de intentar cualquier desafío abierto a la autoridad, la exoneración podía en cambio ampliar los límites de lo permitido y ser un estímulo para que otros hicieran lo mismo.

Sin embargo, en algunos casos se consideró que una sola interrupción de la sumisión se podía excusar ya que no provocaba consecuencias lamentables para el sistema de dominación. Por ejemplo, ante la apelación a la pobreza que presentó Germán Uribe para pagar una multa de veinticinco pesos por amenazar con un cuchillo al alcalde de Manizales, este decidió que "la falta cometida por Germán Uribe, sin embargo de ser grave, no es de aquellas que tienen consecuencias trascendentales [...] que el penado se manifiesta arrepentido por la falta cometida" 48 por lo que la rebajó a cinco pesos. Aquí jugó un papel importante el arrepentimiento del insubordinado, pero también el hecho de que haya habido un cambio de alcalde.

O el caso del comisario José María Serna quien en 1892 contribuyó a exonerar de los cargos de irrespeto a Jesús María Valencia quien en estado de ebriedad le lanzó dos puñaladas. Para el comisario, el ebrio era inconsciente de sus actos y no lo reconocía como autoridad ya que este no se le presentó como tal, solo intentó quitarle el cuchillo; tampoco le "habló en nombre de la ley", ni "le dijo que siguiera para la cárcel". Valencia simplemente le lanzó las puñaladas y salió corriendo por lo que -declara Serna"puedo asegurar que Valencia se tiró a correr a las calles porque estaba ebrio y no lo reconocía como comisario"49. Esta información permitió archivar el caso porque para el alcalde la resistencia fue el resultado de la ebriedad y no de una conciencia para evitar obedecer.

48 "Norberto Gómez a Prefectura departamento del sur, Salamina 13 de marzo de 1874. Procedimiento contra Germán Uribe por desobediencia”, AMM, Fondo Histórico, Caja 17, Libro 57, f. 327.

49 “Contra José María Valencia por resistencia a la autoridad”, AMM, Fondo Histórico, Caja 47, Libro 160, f. 687. Cabe aclarar que de acuerdo al Código Penal no importaba si no tenía uniforme, insignias o identificación, si en el acto de desobediencia se demostraba que el agresor u ofensor tenía conocimiento del carácter público del ofendido o fuera notorio este carácter Art. 170. Ley 19 de 1890. Código Penal (18 de octubre). Bogotá, Imprenta de la Nación. 
Por otro lado, las autoridades tenían claro que un acto de insubordinación pública exitosa podía perforar la superficie uniforme del aparente consenso. De allí, que la Jefatura Municipal de Manizales haya querido poner coto a las desobediencias mediante las multas impuestas a los rebeldes que rechazaran, desconocieran o insultaran a las autoridades legalmente constituidas.

se hace preciso hacer entender que un comisario de policia esta investido de autoridad pública, i como tal es un ejecutor de las órdenes del jefe de policia; i que toda desobediencia a esta clase de empleados es una falta que no debe quedar impugne $[\mathrm{sic}]^{50}$.

O las palabras del jefe municipal Rafael Jaramillo quien manifestó que "La falta de obediencia al jefe de policía, encarna, pues, consecuencias desastrosas para la sociedad, y es de precaución castigarla correccionalmente" La insubordinación no fue un rasgo típico de esta región, pero sí fue característico de los territorios donde la distancia geográfica permitía con mayor fortaleza el uso y el abuso de los "usos y costumbres" para aplicar la ley. Además, hasta la creación del departamento de Caldas, los límites geográficos con otras jurisdicciones eran tenues, lo que facilitaba a los judiciables la evasión de la autoridad.

La dificultad de los empleados con funciones policiales para ejercer el control social en los territorios fronterizos ha sido ampliamente estudiada ${ }^{52} \mathrm{y}$ en este caso particular se debió en gran parte a la forma de reclutamiento de los empleados, su escasa o nula formación, la escasez de recursos y a

50 "Sumarios iniciados y resueltos por la Alcaldía de Manizales entre 1855 y 1870, Sumario Delito Infracción", AMM, Fondo Histórico, Caja 5, Libro 16, Legajo 6, f. 448v.

51 "Causa contra Heraclio López, Ángel María Avendaño, Ramón Giraldo y Pablo Arango por desobediencia, Manizales 29 de mayo de 1876”, AMM, Fondo Histórico, Caja 21, Libro 70, f. 32.

52 Beatriz Patiño, Criminalidad, ley penal y estructura social en la provincia de Antioquia, 1750-1820 (Medellín: UDEA, 1994). Juan Carlos Vélez, "El establecimiento local de la administración de justicia en Antioquia, 1821-1853. El difícil cumplimiento de una promesa republicana". Anuario Colombiano de Historia Social y de la Cultura 40 No. 1, (2013). Juan Carlos Véler, "Desconductadas costumbres y semillas de la discordia. Prácticas de oposición y resistencia a los Jefes Politicos en el Nordeste de Antioquia (1821-1843)", Historia Crítica, 47 (2012): 45-70. Juan Carlos Véles, "Contra el juego y la embriaguez: Control social en la provincia de Antioquia en la primera mitad del siglo XIX", en, Todos somos historia. Control e Instituciones, Tomo 3, Eduardo Dominguez. (Medellin: Universidad de Medellin, 2010), 59-77. César Ballesteros, "Las otras colonizaciones en Antioquia. El caso del Nordeste Antioqueño, 1824-1886", Historia y Sociedad, 16 (2009): 23-48. Nicolás González. Quintero, "Se evita que de vagos pasen a delincuentes: Discursos para la construcción de un sujeto peligroso en Santafé, 17501808" (Tesis pregrado, Universidad Nacional de Colombia-Sede Bogotá, 2010). Germán Colmenares, "El manejo ideológico de la ley en un periodo de transición", Historia Crítica, 4 (1990): 8-31. 
la reacción natural de los judiciables frente a la intromisión del Estado en sus vidas.

La construcción social del respeto y obediencia de los subordinados dependió en buena medida del éxito del sistema de castigos. Con sus dificultades, procuró corregir los irrespetos a la ley y si se atiende al número de casos, pareció funcionar no tanto por la fuerza coercitiva del Estado sino porque los ejemplos pudieron surtir el efecto de generar la prudencia del consentimiento.

\section{LA OTRA CARA DE LA MONEDA. Los ABUSOS DE LA AUTORIDAD}

En 1869 Manuel Villegas Botero, entabló un denuncio en la alcaldía de Manizales porque unos vecinos le insultaron "de la manera más grosera, asquerosa", además embarraron con excremento su puerta y pegaron pasquines infamatorios en las paredes de varias casas. La acusación no siguió el ritmo que el querellante deseaba razón por la cual volvió la semana siguiente a preguntarle al secretario cómo iba la indagación de su caso, obtuvo excusas que justificaban la demora debido a los exámenes de la escuela de niñas y a que los pocos testigos llamados se habían descartado por la informalidad en el interrogatorio. Pasadas tres semanas volvió a preguntar lo mismo y se sorprendió cuando le "enseñaron tres o cuatro declaraciones recibidas con mucho (la misma), sin hacérsele a los testigos sino una sola pregunta, lo que no se hace en casos tales" ${ }^{\text {". }}$. Después de otro tiempo volvió donde el secretario y trajo un nuevo interrogatorio y nombres de más testigos. Pero además increpó al alcalde y secretario a que aceleraran el proceso ya que estaba

"resuelto a todo y que no ando desprevenido y que nunca me he escondido, y que descargo toda responsabilidad a las autoridades de Manizales por lo que pueda ocurrir en lo adelante, si se continúa mirando con indiferencia que la gentuza insolente que desgraciadamente abunda, me insulte de cualquier modo" 54 .

53 "Denuncia por irrespeto contra Manuel Villegas" (Manizales, 1869) AMM, Archivo Municipal de Manizales, Fondo Histórico, Caja 5, Libro 16, f. 470.

54 "Denuncia por irrespeto contra Manuel Villegas" (Manizales, 1869), AMM, Fondo Histórico, Caja 5, Libro 16, f. 470. 
Finalmente, no sabemos cómo terminó el proceso pero tres meses después de la denuncia el sumario culmina con varios folios donde se dice lo mismo "demorado por no haber hallado testigos". Suponemos que no los hallaron, y que si los hubieran encontrado estos coincidirían con las 15 declaraciones recibidas donde se advertía el total desconocimiento del asunto de los pasquines y del excremento, en una coincidencia de palabras que puede ser tan sugestiva como para pensar que se habían puesto de acuerdo en las declaraciones. También pudo ser posible que las energías de Villegas flaquearan para continuar exigiendo a las autoridades la judicialización de los culpables. Tal vez por la homogeneidad de las declaraciones recibidas que evidencian la poca receptividad que tenía en la población o porque notó la desidia de las autoridades para desarrollar el proceso.

En este orden de ideas, la relación entre empleados encargados de mantener el orden y la delincuencia, pudo haber generado un cierto desconcierto con el funcionamiento de la justicia, cuestión que puede explicar parcialmente el uso constante de vías de hecho para la solución de conflictos como lo dejó planteado Manuel Villegas en el ejemplo anterior.

Es necesario advertir que pese a que la insubordinación, insulto y ofensas a la autoridad no fueron una constante durante el período analizado, estas estuvieron presentes al tiempo que los abusos del poder también hicieron presencia esporádica en los juicios sumariales del período estudiado. Ambos tipos dan cuenta del especial interés de las autoridades por controlar las relaciones entre policías y alcaldes con los judiciables, sobre todo porque se trataba de construir el sentido de respeto y la obediencia a las leyes que permitían mantener el orden social y político en la región. De allí, el especial cuidado con el que los jueces manejaron un caso de estafa ocurrido en 1913 y en el que estaban involucrados dos agentes activos de la policía, Luis Carlos Henao y José Mateo Ospina ${ }^{55}$.

La estafa llevada a cabo por los bandoleros, consistió en plantear a sus

55 "Tribunal Superior del Distrito judicial. Dictada en la causa contra Luis Ospina y Rafael Franco por el delito de estafa. Manizales a 13 de octubre de 1913", Revista Judicial de Caldas, 141, Manizales, (diciembre 1 de 1913), 1061. 
víctimas un negocio de falsificación de libras esterlinas que podía dar muchas ganancias. Para inducir a los estafados, estos bandidos - como fueron señalados en el sumario- mostraban unas monedas blancas con la forma de las libras esterlinas, declarando que era "plata metalizada"; luego la sumergían en un líquido y al poco rato la sacaban y limpiaban, quedando aparentemente idénticas a las libras esterlinas; en realidad eran monedas originales ya que la plata metalizada quedaba en el fondo del balde. Así pasaban a pedir un dinero para la participación en el negocio; a algunos les pidieron quince mil, a otros nueve mil u ochocientos dependiendo de las capacidades del estafado.

Luego de entregado el dinero, le pedían al supuesto socio que los acompañaran a "El Tablazo" donde se encontraba la fábrica clandestina de libras esterlinas, pero en el camino siempre aparecían Ospina y Henao, los agentes de policía que revisaban a los transeúntes; aparentemente arrestaban a los sospechosos, decomisaban los químicos y dejaban libre al estafado quien terminaba agradeciendo el gesto de la policía.

En ocasiones, volvían a pedir dinero a los mismos estafados cambiando la estrategia. Enviaban a niños con la mercancía, pero siempre aparecía el policía para decomisar los químicos. Otra variación del plan era que los "policía bandidos" atrapaban al estafado con el dinero, al cual le ofrecían dejarlo en libertad a cambio de dejárselo o de lo contrario lo llevarían preso por participación en un plan de falsificación.

La defensa de los policías acusados consistió en demostrar que "por múltiples que sean los delitos, y por alarma y escandaloso que hayan causado en la sociedad", los agentes no deberían ser tratados como bandoleros sino como ladrones ya que Henao "es ignorante y ha parecido ser de buenas costumbres, que es hombre pobre y merecido confianza como agente de policía, hasta que se le sindicó". El señalamiento de trabajador, buenas costumbres, pobre, respetuoso e ignorante por lo que "puede decirse que es un simple ratero", buscó y consiguió colocar el delito en segundo grado 290 para que fueran tratados con mayor indulgencia.

Estos hechos causaron alarma en la población y los territorios vecinos ya 
que se trataba de agentes de policía involucrados en eventos delictuosos. Evidentemente estas situaciones pudieron haber mellado la autoridad de los uniformados, sobre todo tratándose de vecinos de las mismas comunidades que eran reconocidos públicamente. Aunque el reconocimiento de los convecinos teóricamente era uno de los atributos que contribuía al respeto por la autoridad, en ocasiones la realidad pudo distar de este ideal.

Similar caso ocurrió en 1884 con Daniel Medina quien fue acusado por desobediencia a un comisario. Sin embargo, el caso dio un giro inesperado cuando se demostró que Medina, que también era soldado, había sido ofendido por el comisario quien pretendía "pasar la noche" con Secundina Rodríguez, pareja sentimental de Medina y que se encontraba en alto estado de alicoramiento. Para lograr su cometido el comisario intentó deshacerse de Medina mediante su autoridad pero este se resistió y fue conducido al cuartel ${ }^{56}$. Finalmente, el inspector del distrito exoneró de cargos a Medina porque consideró inoportuno el uso de la fuerza del comisario.

Otro caso de un supuesto abuso de la autoridad ocurrió en 1907 cuando Marco Márquez hirió al gendarme de la Villa de María Epifanio Osorio de dos puñaladas. Nuevamente, aunque el juicio empezó por las heridas, el judiciable logró demostrar que el empleado se extralimitó en sus funciones procurando sin ninguna razón arrestar a su hermano materno Pablo González ya que aparentemente

"sin proferir una palabra más y sin repetirle siquiera la orden que le había dado, levantó un machete de que estaba armado y acometiéndose con él le descargó uno o más golpes, por lo cual Gonzales al verse súbitamente atacado, se fue sobre su agresor y asiéndolo con las manos por el cuerpo, para evitar el que le continuaran tirando, cayeron ambos al suelo y ya en tierra todavía lo hería o intentaba herirlo Osorio con el machete que poseía" ${ }^{27}$.

56 "Sumario criminal por desobediencia a un comisario. Sindicado Daniel Medina", AMM, Fondo Histórico. Caja 32, Libro 105, f. 480.

57 "Tribunal Superior del Distrito judicial. Dictada en la causa contra Marco Márquez por heridas. Municipio de María a 9 de junio de 1907”, Revista Judicial de Caldas, 42, Manizales, julio 15 de 1909 , 335. 
En ese momento intervino Marco A. Márquez, quien tomó parte en la reyerta y con un cuchillo asestó dos puñaladas a Osorio por la espalda. La defensa manifestó que el hecho ocurrió en defensa ya que el funcionario público actuó "de manera gratuita, abusiva e injustificable, y prevalido de su carácter de autoridad, con pretexto de ejercer las funciones de su empleo, atacaba y procuraba herir" ${ }^{2}$, utilizando "medios agresivos y violentos para conseguir la efectividad de una orden inmotivada e injusta". Márquez fue absuelto de los cargos dos años después -aunque ya había estado preso- porque logró demostrar el abuso de la autoridad.

Casos similares ocurrieron con cierta frecuencia. En Circasia en 1908, fue acusado el exalcalde Juan de Jesús Henao, porque hirió a Emilio Trujillo cuando este le reclamó porque en días anteriores siendo alcalde "el negro Henao" lo había "conducido a la cárcel pues que yo no había dado motivo alguno para ello" 59 . La respuesta de Henao fue un disparo en la pierna. Al agente de policía municipal de Manizales Julio Gutiérrez también se le acusó por abuso de autoridad, golpes y malos tratamientos por haber herido con la culata de su rifle a Miguel Caro estando en servicio de centinela en el teatro de la ciudad ${ }^{60}$. De acuerdo al policía, el joven quería entrar atropellándolo a la función cinematográfica; sin embargo el agente fue sentenciado a dos meses de arresto por exceder la fuerza en sus funciones. En 1884 la Inspectoría del distrito de Manizales inició una indagación contra el guarda de las rentas de licores Bernardino Correa porque este aparentemente había abusado de su autoridad golpeando sin causa aparente a Ignacio Arias quien iba cruzando el puente que separaba Villamaría de Manizales ${ }^{61}$.

58 "Tribunal Superior del Distrito judicial. Dictada en la causa contra Marco Márquez por heridas. Municipio de María a 9 de junio de 1907”, Revista Judicial de Caldas, 42, Manizales, julio 15 de 1909, 335.

59 "Tribunal Superior del Distrito judicial. Dictada en la causa contra Marco Márquez por heridas. Municipio de María a 9 de junio de 1907”, Revista Judicial de Caldas, 42, Manizales, julio 15 de 1909, 336.

60 "Tribunal Superior del Distrito judicial. Dictada en la causa contra Julio Gutiérrez por abuso a autoridad. Manizales, 30 de marzo de 1908”, Revista Judicial de Caldas, 21, Manizales, junio 15 de 1908, 166-167.

61 "Sumario por abuso de autoridad iniciado el 13 de octubre de 1884 contra Bernardino Correa", AMM, Fondo Histórico, Caja 32, Libro 105. 
La prensa periódica también hizo eco de este tipo de noticias sobre todo cuando se trataba de atacar políticamente al alcalde de turno que podía usar la policía a su antojo ${ }^{62}$. El periódico El Artesano se quejó del Alcalde de Manizales porque mediante órdenes verbales dadas a sus policías apresaron a unos jóvenes "de lo primero de la sociedad" que prendieron voladores el 12 de octubre por las fiestas ${ }^{63}$. Además del aparente abuso de autoridad del burgomaestre, lo denunciaron porque estaba cobrando 50 centavos de oro como multa a cambio de dejarlos libres ${ }^{64}$. En ocasiones, las autoridades mostraban las mentiras que se construían para desprestigiarlas como ocurrió con el burgomaestre Alejandro Gaviria quien envió una carta al periódico El Artesano, desmintiendo a Antonio Echeverri que había presentado en el mismo periódico una queja por un supuesto abuso de autoridad de la policía que había atacado a Luis F. Gómez, apresándolo y robándole su dinero. El Alcalde logró mostrar que Echeverri había mentido porque no era testigo del suceso ${ }^{65}$.

También parece que hubo alcaldes que cambiaron los límites de tolerancia permitidos y fueron perseguidos por la opinión pública por sus aparentes excesos, cuando posiblemente se trataba de aplicar las normas de manera un poco más literal que sus sucesores. Aquello que denominaban como alcaldadas, que era una burla a bandos y órdenes administrativas de la policía, eran el intento de cambiar las costumbres mediante una presión mayor sobre los comportamientos. Para algunos habitantes este exceso de celo de las autoridades que

"dan en la manía de perseguir muchachos y encarcelar cerdos; a otros les da por envenenar perros; a estos por mantenerse en pleitos y querellas con las mujeres de vida airada; a aquellos por perorar mucho y no decir ni hacer nada, y a los de más allá por publicar muchos bandos para tener el gusto de no ejecutar ninguno; en fin alcaldes hay que apenas tienen ingenio para hacer una alcaldada" $"$.

62 Blanco y Negro, I: 9, octubre 19 de 1912, 5.

63 "Alcaldada", El Artesano. Literatura y Variedades, 17, Manizales, octubre 15 de 1904, 3-4.

64 "Retazos democráticos", El Artesano. Literatura y Variedades, 17, Manizales, octubre 15 de $1904,4$.

65 "Parece Mentira. El Alcalde, Alejandro Gaviria C.", El Artesano, Literatura y Variedades, 25, Manizales, octubre 27 de 1904.

66 "A propósito de Alcaldes", El Iniciador. Literatura, noticias, industria y comercio, 5, Manizales, febrero 7 de 1897, 19. 
La autoridad necesitaba de la teatralización de sus actos - aun cuando estos en principio pudieran ser asumidos como exagerados- porque es sobre esta base que se pretendía constituir la apariencia del respeto a la ley. Sin embargo, en ocasiones no se trataba de aparentar sino de utilizar la legitimidad del aparato coactivo para resolver los conflictos personales, sobreponer los intereses o galantear mostrando su autoridad. De allí que para los subordinados la percepción de la autoridad como irrespetuosa de la ley, pudo haber provocado que se quebrara esa representación de un poder legítimo encarnado en la figura del funcionario y por lo tanto mellado también la autoridad que emanaba de su posición.

\section{Al FINAL, ¿SE OBEDECía A LA AUTORIDAD?}

Bien si se trataba de la comisión de delitos por parte de los funcionarios encargados de mantener el orden o del trato abusivo que dieron a algunos pobladores, al parecer el uso del poder que se derivaba de la posesión de un cargo público como agente, guardia o gendarme permitía la ejecución de medidas de fuerza que en ocasiones provocaban el rechazo de los subalternos. De tal manera que la desobediencia a las órdenes oficiales en ocasiones pudo ser la ejecución de formas de resistir medidas consideradas arbitrarias y por lo tanto fuera de la ley. Así, el uso de la autoridad pudo haber permitido, y por qué no justificado, ciertas venganzas personales entre el agente del orden y el subordinado ${ }^{67}$.

Ante esto cabe preguntarse ¿qué tan arraigada estaba la autoridad? La defensa de Ramón Ortiz por injuriar al alcalde de San Agustín evidencia lo común que resultaban los insultos a los empleados públicos; esta buscaba

67 Un ejemplo de ello fue el caso de Lino Giraldo en el paraje de La Bella del distrito de Pereira en 1922, que en medio de una jornada laboral en su finca, Fernando Ocampo discutió con otro trabajador. Ante la riña, intervino Muñoz quien se presentó como el comisario auxiliar de policía de la fracción. Este supuesto funcionario reconvino a Ocampo y le ordenó guardar el machete, pero Ocampo en lugar de atender se lanzó contra él y le tiró con el machete causándole heridas y persiguiéndolo hasta que Muñoz se vio obligado a huir. Aunque Ocampo fue acusado de resistencia y maltratamiento a la autoridad; logró demostrar que Muñoz no era comisario, lo había sido en 1922 pero esas funciones solo duraban tres meses, limitado su servicio en cada semana a un día de trabajo y otro feriado. Además se comprobó que la intervención de Muñoz se debió a que el afectado en la pelea era Luis Alfredo García, cuñado de Muñoz; por lo tanto actuó como civil defendiendo a un pariente. 
mostrar que si bien los hechos ocurrieron no había que darle importancia ni tomarse de oficio el asunto ya que

\begin{abstract}
"si por cada palabra que se dirija a los empleados públicos y que se estime injuriosa, hubiera de procederse oficiosamente, el número de procesos por tal delito sería incalculable, y en la práctica resultarían graves anomalías y desigualdades, pues dada la diferencia de criterios, lo que para un Juez constituiría el delito de injurias, delito que debía perseguir de oficio, para otro no asumiría investigación alguna"68.
\end{abstract}

Esta cuestión plantea el problema de la definición del delito. La ocurrencia de la desobediencia a la autoridad o el abuso a la misma no es un asunto que esté exento de bemoles ya que la decisión de iniciar una averiguación o un juicio por insubordinación o exceso no es una cuestión de menor importancia. El significado de una determinada acción no es una situación que los historiadores asumamos como dados, definir si se trata de un irrespeto a la autoridad o no, debe ser analizado como una construcción social que depende de los límites entre lo permitido y lo prohibido, entre la ofensa, la injuria y la anécdota; entre aquello que puede ser considerado peligroso porque podría ocasionar problemas mayores al poder establecido y aquello que puede ser considerado cotidiano ${ }^{69}$.

Entonces, ¿había un total irrespeto a las autoridades? Seguramente que no. Los casos mostrados tal vez eran más excepciones que prácticas cotidianas. Sin embargo, se han evidenciado las múltiples complicaciones que debieron afrontar los escasos funcionarios encargados de mantener el orden en el centro occidente colombiano como un rasgo característico del complejo proceso de construcción de la obediencia. A pesar de ello, debió existir un cierto reconocimiento del poder y una aceptación de las reglas de juego dado que se trató más de casos aislados y sin ningún asomo de rebelión frente al poder legítimamente constituido.

68 "Tribunal Superior del Distrito judicial. Dictada en la causa contra Ramón Ortiz por haber faltado al respecto e injuriado al alcalde de San Agustín, señor José Jesús Gallego. San Agustín a 3 de mayo de 1912”, Revista Judicial de Caldas, 142, Manizales, diciembre 15 de 1913, 1069-1071.

69 James Scott. Los dominados..., 242. 
Si se acataba a la autoridad ¿por qué se la respetaba? La respuesta es más compleja y escapa a los límites de este artículo; sin embargo el hecho de que la mayoría de denuncias por abuso hayan fallado en beneficio de los afectados, evidencia una cierta simetría ejecutada por la justicia para equilibrar una balanza que parecía estar inclinada.

Dar la razón a las víctimas era no solo impartir justicia, sino enviar un mensaje a las autoridades y subordinados: para los primeros, que debían actuar de acuerdo a las normas. Para los segundos, que podían resistir un alcalde o policía injusto pero no al Estado. Esta separación entre malos funcionarios y Estado se puede observar en las declaraciones del fiscal que se encargó de demostrar que una injuria contra el Inspector del corregimiento de Colón no era una ofensa a la persona en su carácter particular, ni que "la resistencia que hizo el reo a una providencia de la autoridad", era un acto de desobediencia a la persona, ya que con ello se "afecta al Estado en su actividad jurídica, puesto que el propósito del delincuente es paralizar la acción de la autoridad", y porque con el desacato se ofende al empleado en su carácter oficial, caso en el cual el funcionario "viene a ser como una personificación del Estado, al cual se lesiona con el hecho" y por lo cual se "le castiga de una manera especial y más severa"70.

Para concluir, en este trabajo se señalaron las difíciles condiciones en las cuales se intentó imponer la autoridad en una región en proceso de consolidación. Además, se mostró cómo la teatralidad del poder y la puesta en práctica de dos formas de dominación (consenso y coacción), constituyeron la base sobre la cual una burocracia en formación intentó aplicar la justicia y legitimar el orden social que representaban. Frente a este escenario, y aunque resulta un exabrupto lingüístico considerarlos como una burocracia en el sentido estricto, en muchos distritos, parajes y corregimientos estudiados en este trabajo el inspector, guardia, gendarme y policía fueron tal vez los únicos representantes del Estado que los habitantes habrían visto a lo largo de sus vidas.

70 "Tribunal Superior del Distrito judicial. Dictada en la causa contra Manuel Díaz por los delitos de homicidio y resistencia a la autoridad. Calarcá a 20 de febrero de 1916", Revista Judicial de Caldas, 219, Manizales, agosto 1 de 1917, 151. 
Si bien la puesta en marcha de estos elementos debe reposar, como se señaló líneas arriba, sobre la base de una burocracia moderna; en este trabajo se observaron las dificultades que representaba el proceso de construcción de dicha burocracia. Las demoras en los juicios, la falta de recursos, la lenta marcha de los procedimientos judiciales, y en algunos casos los pocos conocimientos de muchos sujetos que debían impartir justicia y mantener el gobierno (e incluso hasta las distancias geográficas), constituyeron verdaderos obstáculos en el proceso de consolidación de la "burocracia moderna” y en el acicate que sembró la desconfianza frente a los servidores públicos.

Aunado a estos hechos, la intrincada maraña de relaciones (de consanguineidad, amistad y compadrazgo) y conflictos existentes entre los funcionarios estatales y las sociedades locales coadyuvaron a complejizar el ejercicio del poder. Pese a lo cual, se evidencia un asentamiento de la autoridad en estos territorios que tenían expresión no solo en los ejercicios coercitivos del Estado, sino también en el uso de la justicia por parte de los subordinados quienes combinaban la "aplicación de justicia" por su propia mano, con las solicitudes ante los jueces de primera y segunda instancia. En algunos casos, estos fenómenos llevaron a desobedecer las órdenes de funcionarios y en otros a golpear, gritar o amenazar a los empleados.

\section{BibliografíA}

\section{Fuentes de archivo}

Archivo Historial, Manizales, I: 6, enero de 1919.

Archivo Histórico de Manizales (AMM), Manizales, Fondo Histórico.

Blanco y Negro, Manizales, I: 9, octubre 19 de 1912.

Ley 19 de 1890. Código Penal (18 de octubre). Bogotá: Imprenta de la Nación.

Código Penal (Junio 27). El Senado y la Cámara de Representantes de la Nueva Granada, reunidos en Congreso, han venido en decretar y decretan el siguiente Código Penal. Dado en Bogotá a 29 de mayo de 1837.

El Artesano. Literatura y Variedades, Manizales-Colombia. 17, (octubre 15 de 1904), 25, octubre 27 de 1904. 
El Iniciador. Literatura, noticias, industria y comercio, Manizales, 5, febrero 7 de 1897; 8, febrero 28 de 1897; 9, marzo 7 de 1897.

Juzgado Promiscuo de Salamina. Salamina, Colombia. Fondo Archivo Antiguo.

Pombo, Lino de (ed.). Recopilación de Leyes de la Nueva Granada. Bogotá: Imprenta de Zoilo Salazar, 1845.

Revista Judicial de Caldas, Manizales, 122, febrero 15 de 1913; 141, diciembre 1 de 1913; 142, diciembre 15 de 1913; 212, abril 15 de 1917; 219, agosto 1 de 1917; 42, julio 15 de 1909; 21, junio 15 de 1908.

\section{Fuentes Secundarias}

Balandier, George. El poder en escenas. De la representación del poder al poder de la representación. Barcelona: Paidós, 1994.

Ballesteros, César. "Las otras colonizaciones en Antioquia. El caso del Nordeste antioqueño, 1824-1886", Historia y Sociedad, 16 (2009): 23-48.

Patiño Beatriz. Criminalidad, ley penal y estructura social en la provincia de Antioquia, 1750-1820. Medellín: UDEA, 1994.

Bloch, Marc. Introducción a la Historia. México: FCE, 1979. [primera edición de 1949].

Cohen, Albert. Delinquent Boys. The Culture of the Gang. New York: The Free Press, 1955.

Colmenares, Germán. "El manejo ideológico de la ley en un período de transición”, Historia Crítica, 4 (1990): 8-31.

Forte, Ricardo, y Guillermo Guajardo (Coord.). Consenso y Coacción. Estado e instrumentos de control político y social en México y América Latina (Siglos XIX y XX). México: El Colegio de México, El Colegio Mexiquense, 2000.

Fradkin, Raúl. "Justicia, policía y sociedad rural. Buenos Aires, 17801830”. En Las escalas de la historia comparada. Dinámicas sociales, poderes políticos y sistemas jurídicos, Tomo II, coordinadoras Marta Bonaudo, Andrea Reguera, Blanca Zeberio. Buenos Aires: Miño y Dávila SRL, 2008.

González Quintero, Nicolás. "Se evita que de vagos pasen a delincuentes: Discursos para la construcción de un sujeto peligroso en Santafé, 1750-1808”. Tesis pregrado, Universidad Nacional de Colombia-Sede Bogotá, 2010. 
Grossi, Paolo. Mitología jurídica de la modernidad. Madrid: Editorial Trotta, 2003.

Hall, Stuart. "El trabajo de la representación”. En Representation: Cultural Representations and Signifying Practices, editor Stuart Hall. Londres: Sage Publications, 1997.

Hobsbawn, Eric. Bandidos. Barcelona: Crítica, 2011.

Levi, Giovanni. "Reciprocidad mediterránea", Hispania Vol. LX/1 No. 204 (2000): 103-126.

Mallon, Florencia. "Reflexiones sobre las ruinas: formas cotidianas de formación del Estado en el México decimonónico". En Aspectos cotidianos de la formación del Estado. La revolución y la negociación del mando en el México moderno, compiladores Joseph Golbert M. y Daniel Nugent. México: Ediciones Era, 2002.

Monsalvo Mendoza, Edwin, y Ana María Bedoya Sánchez. "El complejo establecimiento del orden de policía en una sociedad de frontera. Manizales 1853-1871", Virajes. Revista de Sociología y Antropología Vol. 16 No. 2 (2014): 41-65.

Monsalvo Edwin, Suárez Miguel y David Herrera. "Conflictividad, delincuencia y justicia en el Departamento de Caldas, 1900-1925”, Historia y Espacio, 45 (2015): 97-118.

Monsalvo Mendoza, Edwin y López Castrillón, Héctor Miguel. "La acción policial en un territorio periférico. La Justicia en la Parroquia de Manizales 1855-1865”, Memoria y Sociedad, Vol. 18 No. 37 (2014): 113-130.

Scott, James. Los dominados y el arte de la resistencia. México: Ediciones Era, 2000.

Skocpol, Theda. Los Estados y las revoluciones sociales. México: Fondo de Cultura Económica, 1983.

Tilly, Charles. Coerción, capital y estados europeos. Buenos Aires: Alianza, 1993.

Vélez, Juan Carlos. "Contra el juego y la embriaguez. Control social en la provincia de Antioquia en la primera mitad del siglo XIX". En Todos somos historia. Control e Instituciones, Tomo 3 Eduardo Domínguez. Medellín: Universidad de Medellín, 2010, 59-77.

Vélez, Juan Carlos. "Desconductadas costumbres y semillas de la discor- 
dia. Prácticas de oposición y resistencia a los Jefes Políticos en el Nordeste de Antioquia (1821-1843)", Historia Crítica No. 47 (2012): 45-70.

Vélez, Juan Carlos. "El establecimiento local de la administración de justicia en Antioquia, 1821-1853. El difícil cumplimiento de una promesa republicana", Anuario Colombiano de Historia Social y de la Cultura Vol. 40 No. 1 (2013).

Weber, Max. Economía y Sociedad. México: FCE, 1986.

Para citar este artículo: Monsalvo Mendoza, Edwin; Chapman Quevedo, Willian y Suárez Araméndiz, Miguel. "El funcionario viene a ser como una personificación del Estado". Conflictos y límites de la autoridad en 300 el centro occidente colombiano, 1850-1925", Historia Caribe Vol. XII No. 30 (Enero-Junio 2017): 267-300. DOI: http://dx.doi.org/10.15648/ hc. 30.2016 .10 